\title{
REVERSE ENGINEERING BODY FENDER MOBIL ESEMKA RAJAWALI II DENGAN MEMBANDINGKAN HASIL PENGUKURAN DENGAN MENGGUNAKAN COORDINATE MEASURING MANUAL MACHINE DAN LASER SCANNERARTICULATED MEASUREMENT ARMS
}

\author{
Akhmad Pujiono $^{1}$, Supriyono ${ }^{2}$ dan Joko Sedyono ${ }^{2}$ \\ ${ }^{1}$ Politeknik Muhammadiyah Pekalongan, \\ Jl.Raya Pahlawan No. 10 Kajen 51161 Telp/Fax (0285) 385313 \\ ${ }^{2} J u r u s a n$ Teknik Mesin Universitas Muhammadiyah Surakarta, \\ Jl. A. YaniTromol Pos I Pabelan, Kartosuro \\ email:Akhmad_Pujiono@yahoo.com
}

\begin{abstract}
ABSTRAK
Penelitian ini menggunakan metode reverse engineering yang bertujuan untuk mendapatkan gambar 3 D surfacefendermobilEsemkaRajawali II sertamembandingkan hasil pengukuran fender dengan menggunakan dua langkah pengukuran (scanning). Langkah pertama adalah pengukuran (scanning) pada fender mobil Esemka Rajawali II dengan menggunakan alat ukur 3D manual, sedangkan Langkah kedua adalah pengukuran (scanning) fender mobil Esemka Rajawali II dengan menggunakan 3D Laser Scanner Articulated Measurement Arms (LSAMA). Data yang diperoleh dari proses pengukuran (scanning) dari kedua alat tersebut diatas berupa titik koordinat (point cloud) x,y dan z, yang selanjutnya data titik koordinat tersebut dimasukkan ke softwere solidworks untuk membuat gambar part 3D surface fender mobil esemka Rajawali II. Setelah proses membuat gambar part 3D surface fender selesai dilakukan, tahapan selanjutnya membandingkan hasil scanning (pengukuran) dari kedua alat ukur tersebut. Titik (point) koordinat pada komponen fender merupakan titik (point) bantu yang digunakan untuk menerangkan bentuk dari surface pada fender tersebut. Semakin banyak jumlah dari point yang digunakan maka semakin bagus bentuk fender yang dihasilkan, hal tersebut disebabkan antara point satu maupun point yang lainnya dihubungkan melalui garis sebelum dilakukan surface pada softwere solidworks. Jumlah point maupun letak dari point tersebut diberikan secara acak (random) pada komponen fender tersebut. Dari kedua alat ukur tersebut yaitu $3 D$ (LSAMA) dan alat ukur 3D manual, menggunakan jumlah point koodinat yang sama.
\end{abstract}

Kata kunci: 3D Laser Scanner Measurement Arms, Alat ukur 3D manual, Fender, Solidworks

\begin{abstract}
This research uses reverse engineering method which aims to get $3 D$ surface fender images of Esemka Rajawali II car and compare the result of fender measurement by using two steps of measurement (scanning). The first step is the measurement on the Esemka Rajawali II car fender using a manual 3D measuring instrument, while the second step is the measurement of Esemka Rajawali II car fender using 3D Laser Scanner Articulated Measurement Arms (LSAMA). Data obtained from the above
\end{abstract}


point of coordinates (point cloud) $x, y$ and $z$, which then the data point coordinates are inserted into softwere solidworks to create images of $3 D$ fender part of the car surface esemka Rajawali II. After the process of making a 3D part surface fender image completed, the next stage compares the results of the two measuring instruments. The point (coordinate) of the fender component is the assist point used to explain the shape of the surface of the fender. The number of points used will affect the shape of the resulting fender, it is caused between the point one or the other point connected through the line before the surface on softwere solidworks. The number of points and the location of the point is randomly assigned to the fender component. Of the two measuring tools are $3 D$ (LSAMA) and manual $3 D$ measuring instruments, using the same number of koodinat points. Using $3 D$ (LSAMA) has a better measurement precision than a manual $3 D$ measuring instrument.

\section{Keywords: 3D Laser Scanner Measurement Arms, 3D manual gear, Fender, Solidworks.}

\section{PENDAHULUAN}

Mobil Esemka Rajawali II merupakan salah satu produk andalan dari pengembangan mobil nasional dilndonesia. Sebagai produk awal dari pengembangan mobil nasional tidak menutup kemungkinan perlu dilakukan beberapa perbaikan maupun penyempurnaan dari produk tersebut. Berbagai upaya telah dilakukan untuk mendukung kesempurnaan dari program mobil nasional tersebut.

Metode reverse engineering atau lebih dikenal dengan metoda rekayasa ulang merupakan suatu metode untuk memperoleh data geometri dari produk yang telah ada dan merekonstruksi ulang menjadi model gambar tiga dimensi sehingga waktu produksi dapat diminimalkan (Hussain dkk, 2008). Dengan kata lain Reverse Engineering dapat di definisikan "menganalisa suatu sistem melalui identifikasi komponen-komponennya dan keterkaitan antar komponen, serta mengekstraksi dan membuat abstraksi dan informasi perancangan dari sistem yang dianalisa tersebut". (Paulic,2013).

Febriantoko (2012) melakukan reverse engineering dengan obyekmenggunakan mini trukEsemka, Penelitianinibertujuan mendokumentasi serta mengklarifikasi bagian komponen berdasarkan induk dari assembly yang utuh, pemberiannama, dankode. Pada penelitian yang lain (Filho, 2014) melakukan reverse engineeringpadabagian-bagianpermukaan yang bentuknya rumit serta komplek, mulai dari pengukuran bentuk serta melakukan pengolahan data. Alat ukur yang digunakan pada penelitian ini Coordinate Measuring Arm yang dilengkapi dengan sensor serta laser scanner, sedangkan data diolah dengan menggunakan Computer-Aided Design (CAD).

Piratelli, (2014) melakukan reverse engineering pada mobil sport dengan menggunakan Coordinate Measuring Arm dengan sensor probe dan laser scanner tiga dimensi. Data yang didapat dari Coordinate Measuring Arm diolah dengan menggunakan CAD. Kus (2009) melakukan reverse engineering membuat model 3D dengan menggunakan $\mathrm{CAD}$ dari komponen yang tidak memiliki dokumentasi.

\section{METODE PENELITIAN}

Tempat penelitian ini, dilakukan dilaboratorium Teknik Mesin gedung $\mathrm{H}$ Universitas Muhammadiyah Surakarta dan di Pusat Layanan Uji Material dan Permesinan Dinas Perindustrian dan Perdagangan Kabupaten Tegal UPTD Laboratorium Perindustrian dengan alamat Jalam Dampyak Km 4 Tegal. 

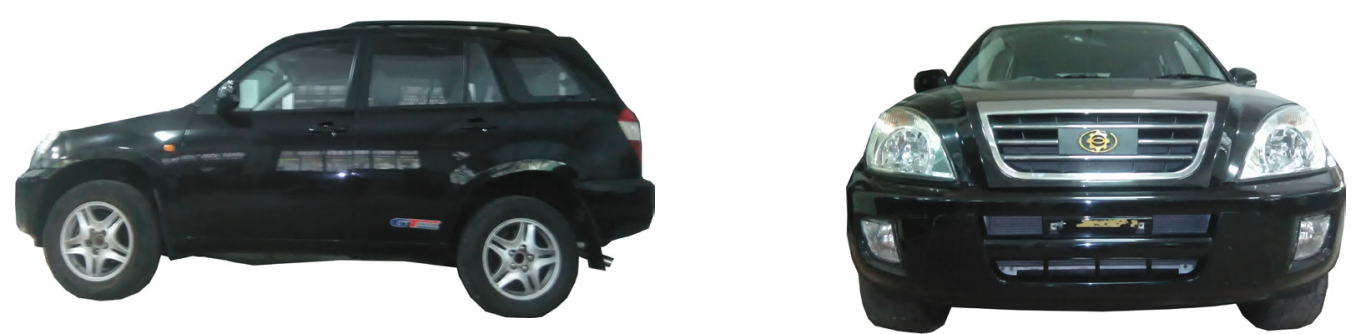

Gambar 1. Mobil Esemka Rajawali II

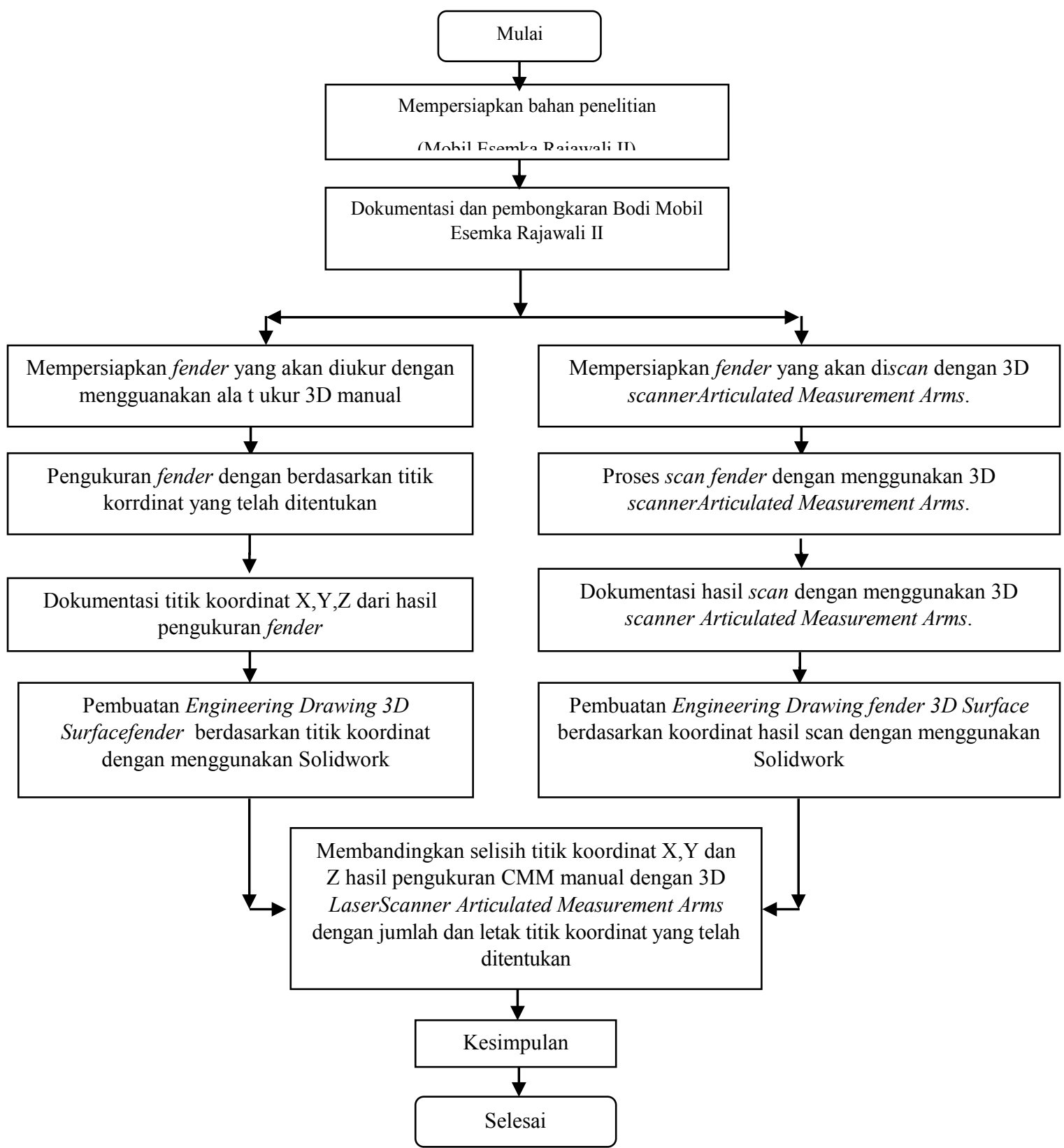

Gambar 2. Gambar Diagram Alir Reverse Engineering

Berdasarkan diagram alir reverse engineering diatas dapat dimaknai bahwa proses reverse engineering pada fender dilakukan dengan beberapa tahapan, yaitu: tahapan pengukuran (scanning), tahapan pengolahan data dengan softwere solidworks, tahapan pembuatan Engineering Drawing 3D surface fender. Dan membandingkan selisih titik koordinat X,Y 
dan $\mathrm{Z}$ hasil pengukuran CMM manual dengan 3D (LSAMA)dengan jumlah dan letak titik koordinat yang telah ditentukan.

\section{Tahapan pengukuran (scanning)}

Proses pengukuran (scanning) bertujuan untuk mendapatkan data dari fender mobil Esemka Rajawali II. Proses pengukuran (scanning) dilakukan dengan menggunakan dua alat ukur yang berbeda yaitu alat ukur 3D manual dan 3D (LSAMA). Setelah fender dari mobil Esemka Rajawali II terlepas dari mobil, kemudian dilakukan pengukuran dengan pengambilan titik koordinat pada permukaan dari fender mobil Esemka tersebut. Alat ukur 3D manual yang digunakan mempunyai desain seperti gambar dibawah ini:

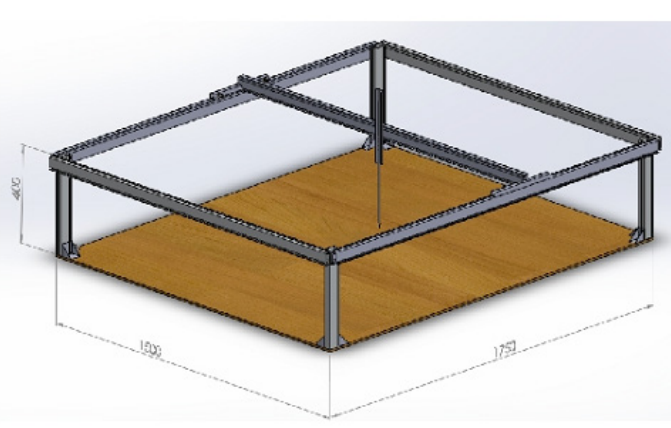

(a)

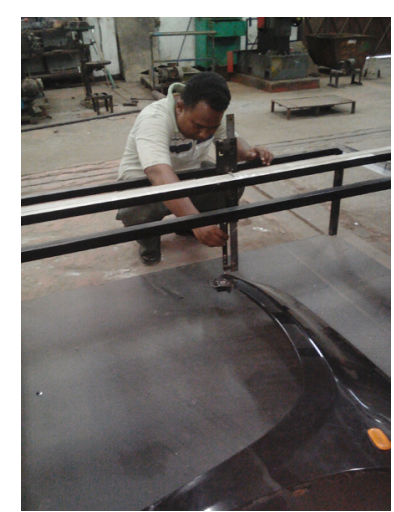

Gambar 3. Gambar (a) Desain dari alat ukur 3D Manual.

(b) Proses pengukuran fender dengan alat ukur 3D manual.
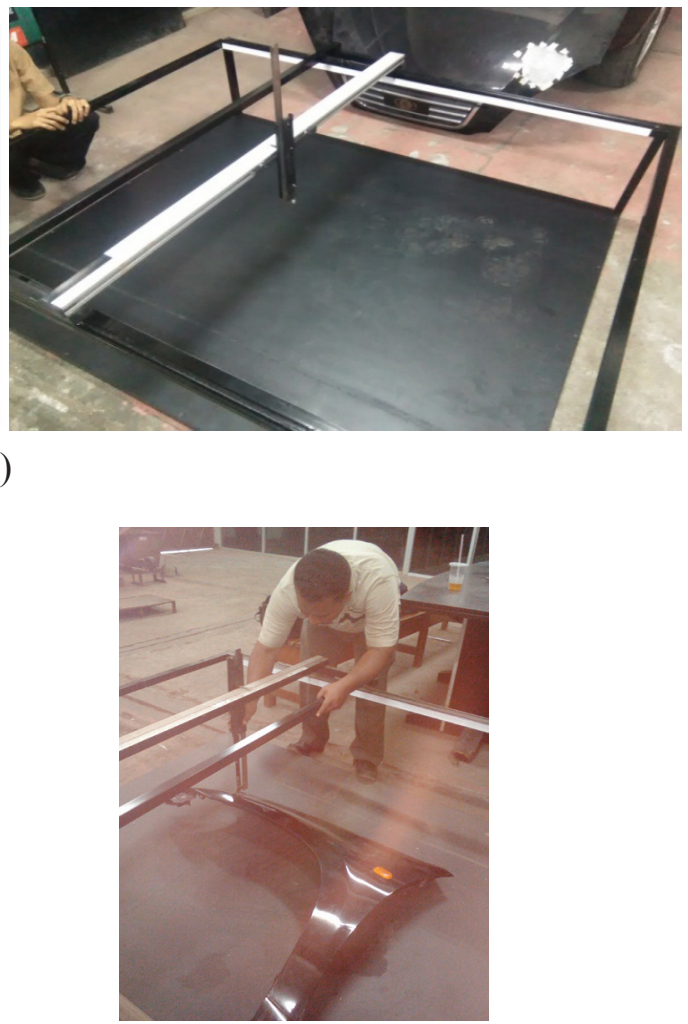

(b)

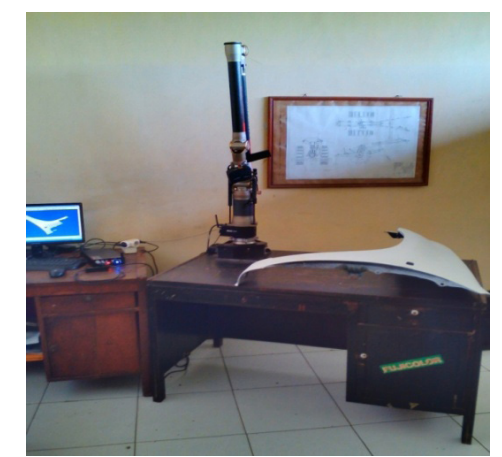

Gambar 4. 3D Laser Scanner Articulated Measurement Arms 


\section{Tahapan Pengolahan Data}

Pada tahapan pengolahan data dilakukan dengan Softwere Solidworks Premium 2014. Data yang hasil pengukuran (scanning) dengan menggunakan alat ukur 3D manual maupun dengan 3D (LSAMA)berupa titik koordinat yang kemudian dimasukkan ke Softwere Solidworks. Berikut tahapan pengolahan data dengan alat ukur 3D manual adalah titik koordinat dimasukkan ke Softwere Solidworks yang kemudian menyatukan titik yang satu dengan titik yang lainnya dengan menggunakan kurva sehingga terbentuk sebuah kurva outer dari fender mobil Esemka Rajawali II. Tahapan berikutnya setelah kurva terbentuk, maka permukaan dapat dibuat dengan metode surface.

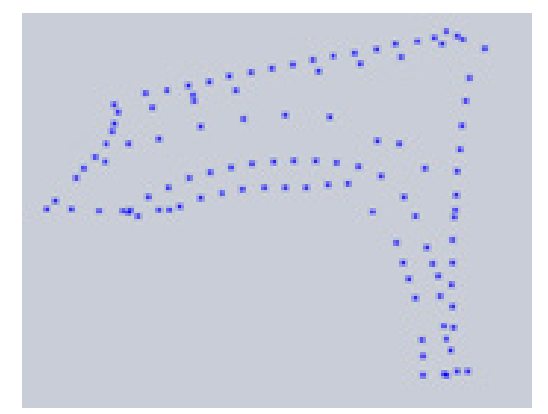

Gambar 5. Tahapan Pengolahan Data dari alat ukur 3D manual

Pada pengolahan data dari 3D (LSAMA)adalah fender mobil Esemka Rajawali II yang sudah terpisah dari mobil dibersihkan dari kotoran maupun debu yang menempel, kemudian fender tersebut dilapisi dengan cat warna putih doop seperti gambar dibawah ini:

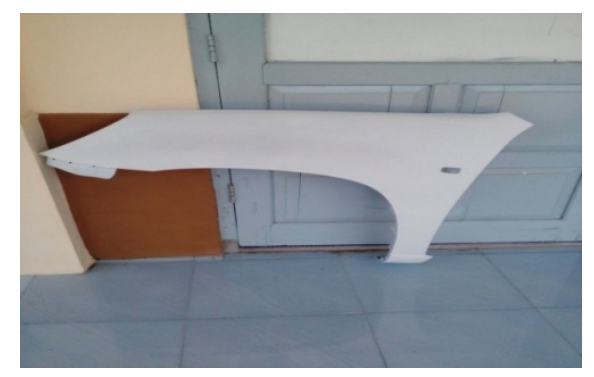

Gambar 6. Fender yang sudah dilapisi cat warna putih

Pelapisan warna putih doop pada fender bertujuan agar sinar laser dari 3D (LSAMA) dapat terpantulkan dengan baik sehingga proses scanning pada fender tersebut dapat diperoleh data point cloud seperti yang diharapkan. Dibawah ini merupakan gambar dari hasil scanning dari 3D (LSAMA).
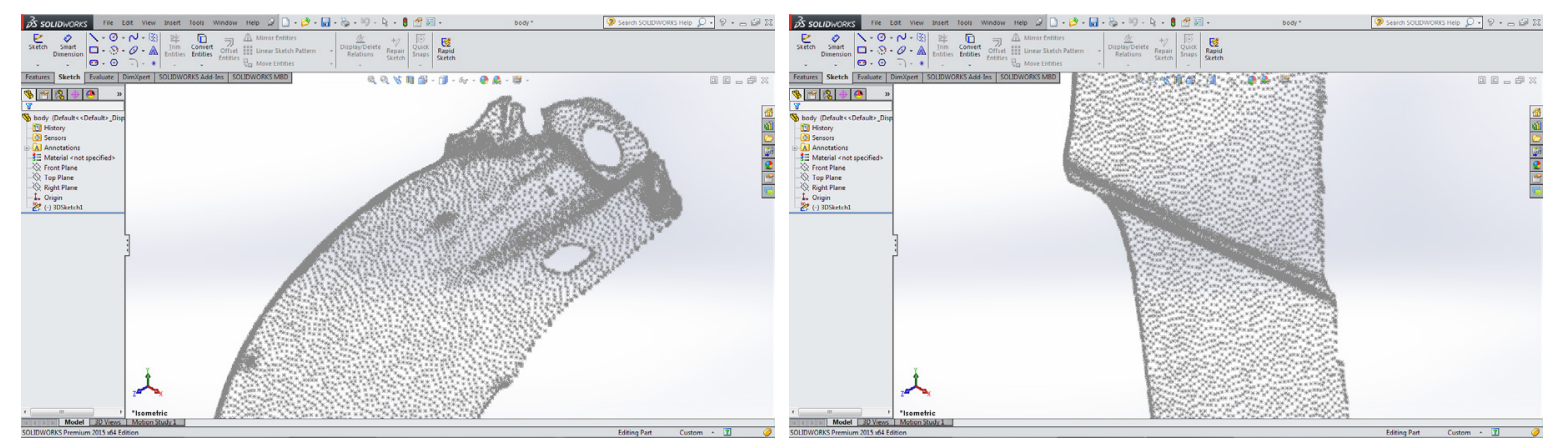

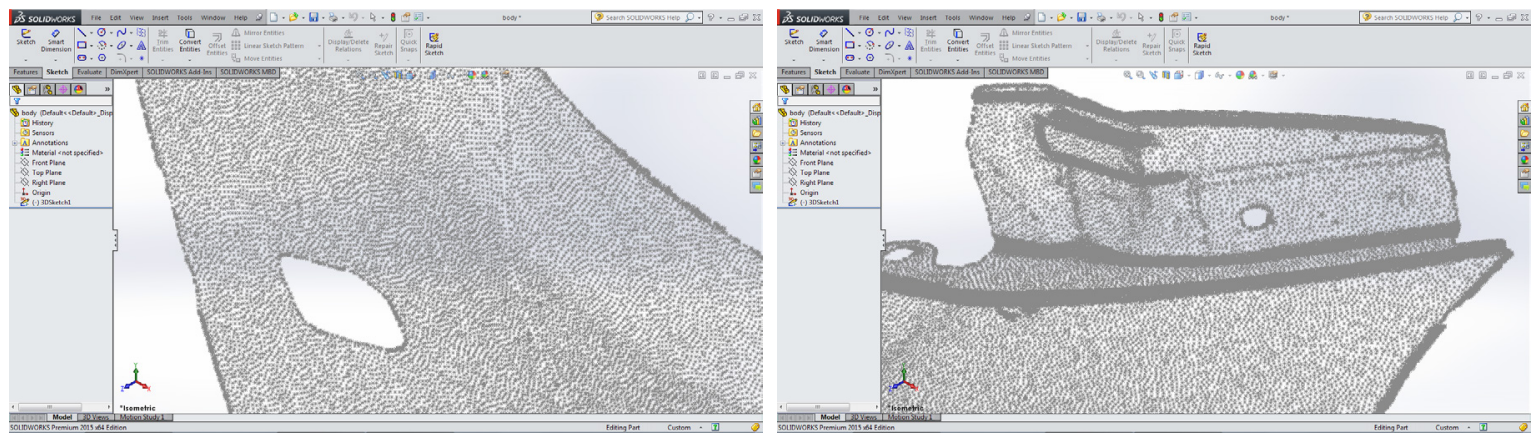

Gambar 7. Hasil Scanning dari 3D Laser Scanner Articulated Measurement Arms

\section{Tahapan Pembuatan Engineering Drawing 3D surface fender}

Pada tahapan ini hasil dari pengolahan data titik koordinat yang dihasilkan dari alat ukur 3D Manual maupun 3D (LSAMA)selanjutnya dibuat gambar 3D surface fender dengan menggunakan softwere solidworks seperti gambar dibawah ini:

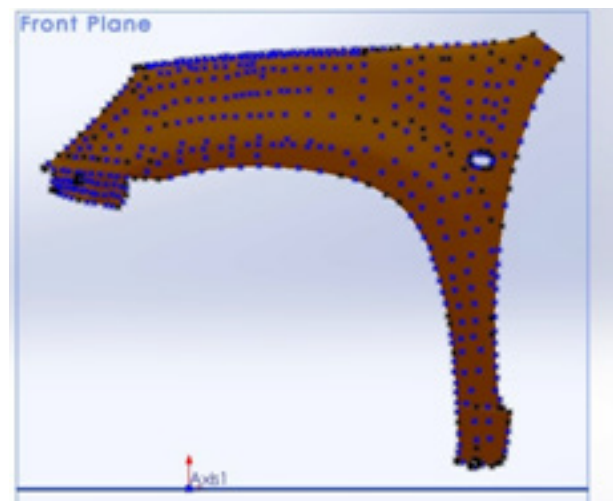

(a)

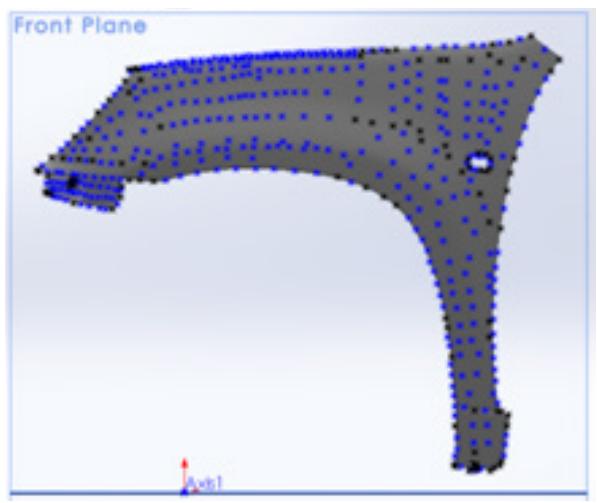

(b)

Gambar 8. (a) 3D surface fender dari alat ukur 3D Manual

(b) 3D Surface Fender dari 3D Laser Scanner Articulated Measurement Arms. Membandingkan Hasil Pengukuran Dengan Menggunakan Coordinate Measuring 3D Manual dan 3D Laser Scanner Articulated Measurement Arms.

Gambar 3D surface fender yang telah dibuat seperti gambar 6.(a) dan (b) diatas, maka langkah selanjutnya menentukan letak maupun jumlah point pada gambar 3D surfacefender mobil Esemka Rajawali II tersebut. Point pada komponen fender merupakan point bantu yang digunakan untuk menerangkan bentuk dari surface pada fender tersebut. Semakin banyak jumlah dari point yang digunakan maka semakin bagus bentuk fender yang dihasilkan, hal tersebut disebabkan antara point satu maupun point yang lainnya dihubungkan melalui garis sebelum dilakukan surface pada softwere solidwork.

Jumlah point maupun letak dari point tersebut diberikan secara random pada komponen fender tersebut. Jumlah point yang digunakan sebanyak 484 point, dengan jumlah point tersebut diharapkan mampu untuk menerangkan serta membuat bentuk surface dari komponen fender yang hampir menyerupai bentuk asli dari mobil Esemka tersebut. Adapun penomoran dilakukan agar dalam pembacaan titik koordinat dengan menggunakan dua metode tersebut dapat lebih mudah untuk dilakukan. Gambar dibawah menerangkan tentang urutan penomoran baik dari alat ukur 3D manual maupun 3D (LSAMA). 

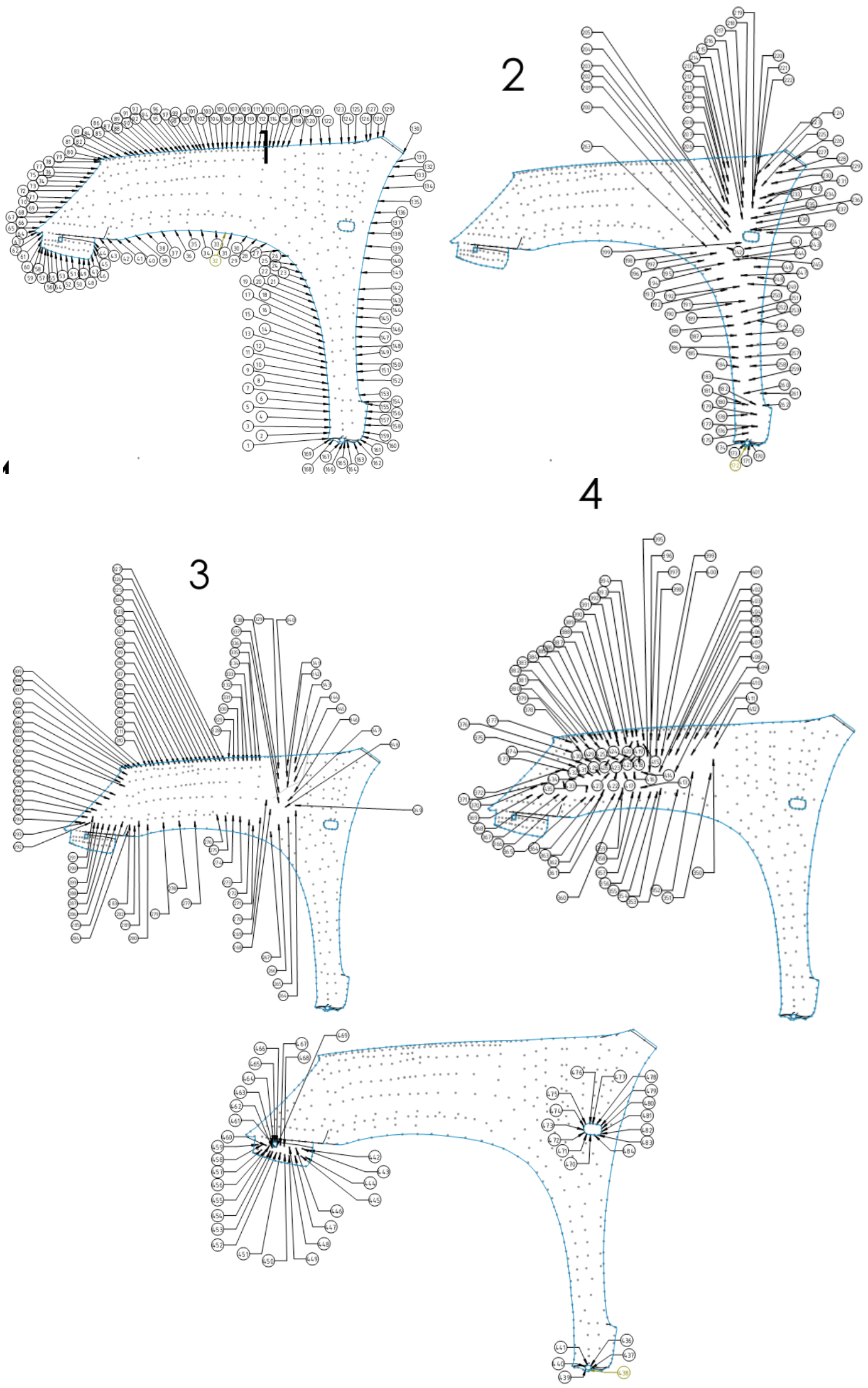

Gambar 9. Urutan penomoran point pada komponen fender pada 3D Laser Scanner Measurement Arms.

no. 1 - 169, (2) no. 170 - 262, (3) no. 263 - 349, (4) no. $350-435$, (5) no. 436 - 484 

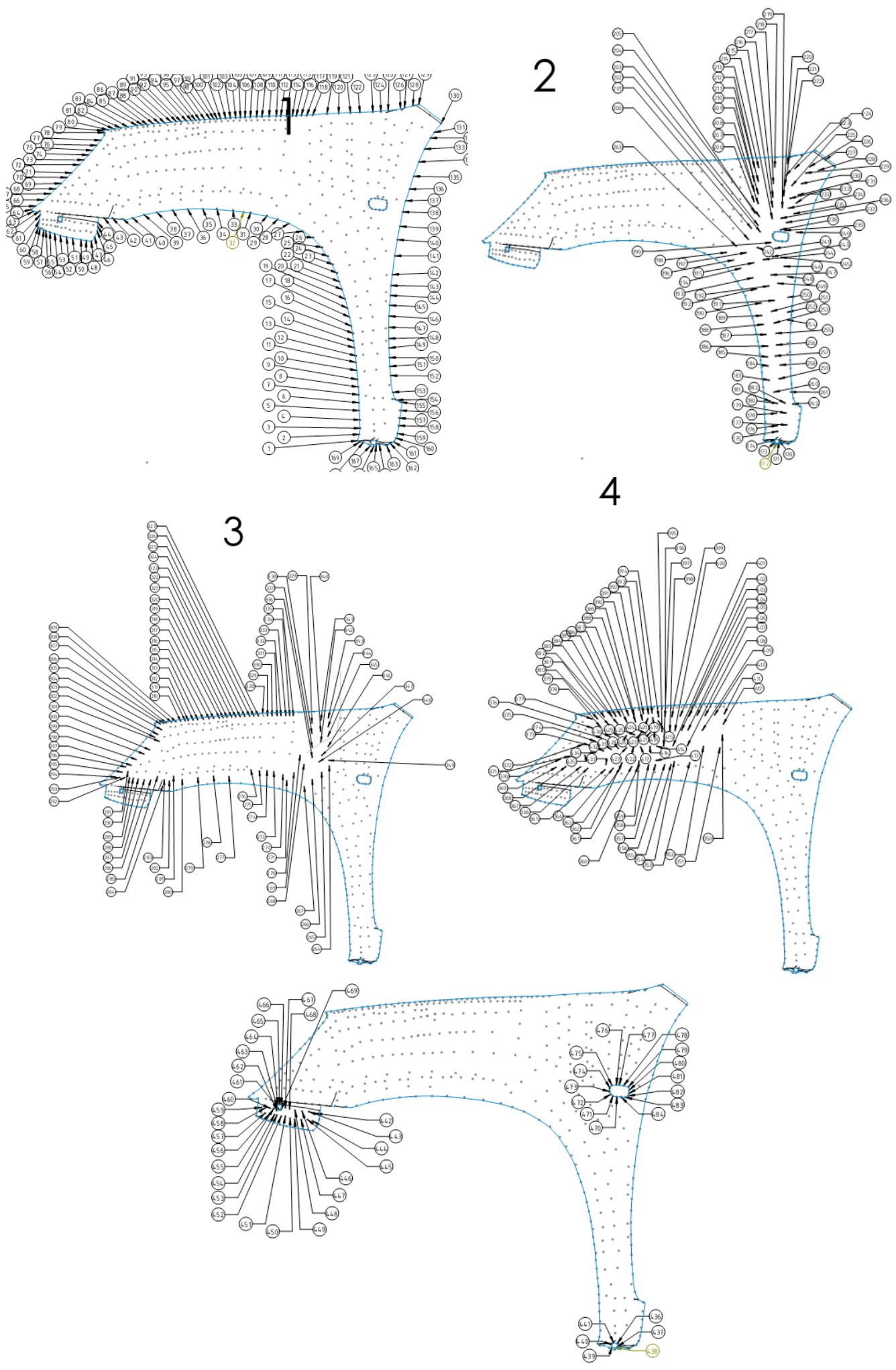

Gambar 10. Urutan penomoran point pada komponen fender pada Alat Ukur 3D Manual (1) no. 1 - 169, (2) no. 170 - 262, (3) no. 263 - 349, (4) no. 350 - 435, (5) no. 436 - 484

\section{HASIL DAN PEMBAHASAN}

Engineering drawing fender mobil Esemka Rajawali II didapatkan dari pengolahan data titik koordinat yang dihasilkan baik dari alat ukur 3D manual maupun 3D (LSAMA)seperti terlihat pada gambar dibawah ini: 

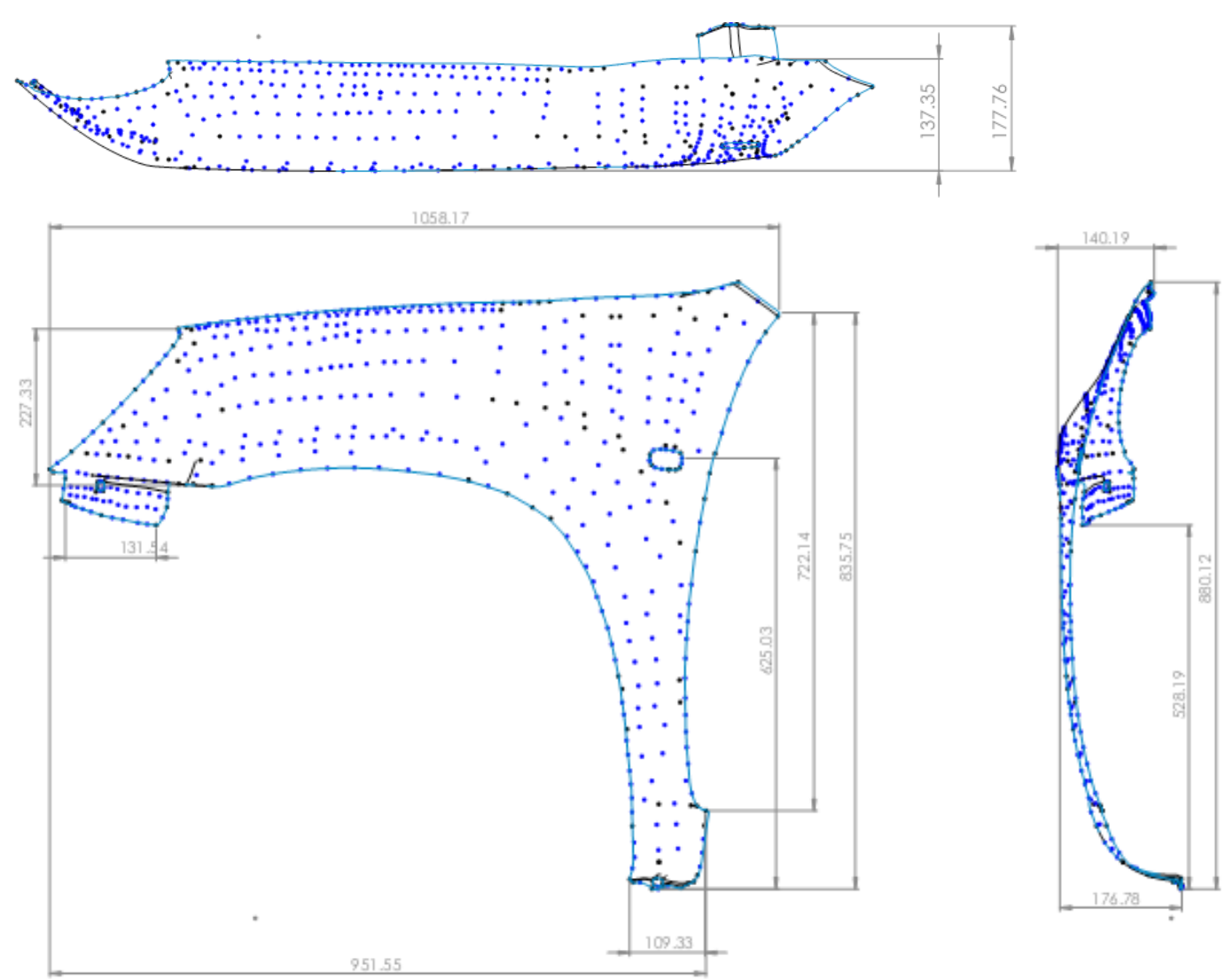

(a)
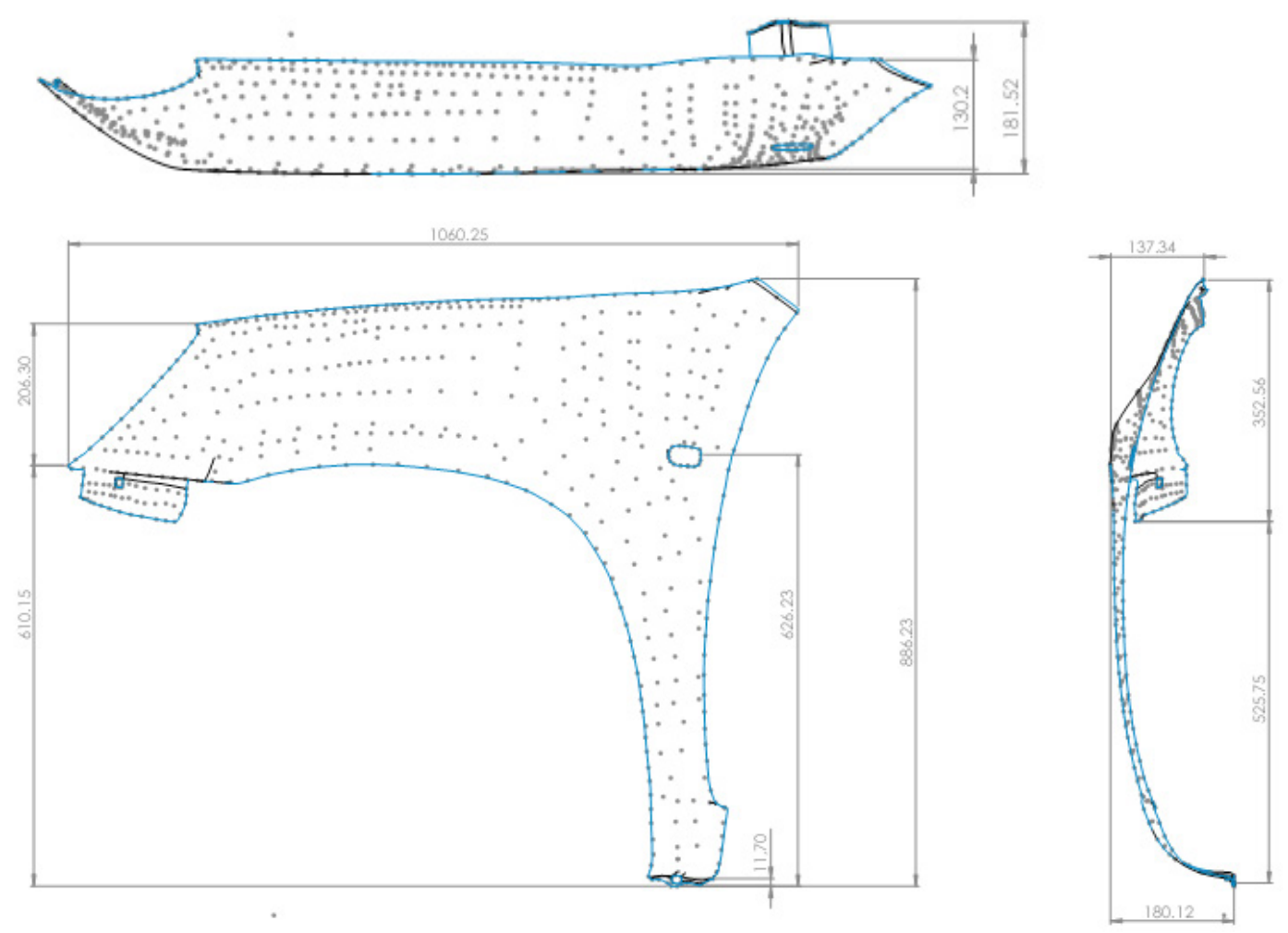

(b)

Gambar 11. (a) Engineering Drawing Fender dari 3D Laser Scanner Measurement Arms (b) Engineering Drawing Fender dari Alat Ukur 3D Manual 
Dari gambar diatas terdapat perbedaan pada fender mobil esemka Rajawali II. Perbedaan hasil ukur dari alat ukur 3D manual dengan 3D (LSAMA)pada dimensi panjang fender 2,08 $\mathrm{mm}(1060,25 \mathrm{~mm}-1058,17 \mathrm{~mm})$. perbedaan lebar fender adalah 3,34 $\mathrm{mm}(180,12 \mathrm{~mm}-$ $176,78 \mathrm{~mm})$. Selain itu selisih pemgukuran pada tinggi dari fender adalah $6,11 \mathrm{~mm}(886,23 \mathrm{~mm}$ $-880,12 \mathrm{~mm})$. Tinggi lengkungan dudukan lampu depan adalah 1,03 $\mathrm{mm}(207,33 \mathrm{~mm}-206,3$ $\mathrm{mm})$. Lebar fender bagian atas adalah 2,79 mm ( 140,13 mm - 137,34 mm). Perbandingan dimensi hasil pengukuran pada fender mobil Esemka Rajawali II tersaji pada tabel dibawah ini:

Tabel 1. Perbandingan dimensi hasil pengukuran pada fender mobil Esemka Rajawali II

\begin{tabular}{llcccc}
\hline No & Nama Bagian & $\begin{array}{c}\text { 3D Scanner } \\
\text { Measurement } \\
\text { Arms }(\mathbf{m m})\end{array}$ & $\begin{array}{c}\text { 3D } \\
\text { manual } \\
(\mathbf{m m})\end{array}$ & $\begin{array}{c}\text { Selisih Hasil } \\
\text { Pengukuran } \\
(\mathbf{m m})\end{array}$ & $\begin{array}{c}\text { Selisih Hasil } \\
\text { Pengukuran } \\
(\mathbf{\%})\end{array}$ \\
\hline 1 & Panjang fender & 1058,17 & 1060,25 & 2,08 & 0,20 \\
2 & Lebar fender & 176,78 & 180,12 & 3,34 & 1,85 \\
3 & Tinggi fender & 880,12 & 886,23 & 6,11 & 0,69 \\
4 & Tinggi dudukan lampu depan & 207,33 & 206,3 & 1,03 & 0,50 \\
5 & Lebar fender bagian atas & 140,13 & 137,34 & 2,79 & 2,03 \\
\hline Rata - rata & 2462,53 & 2470,24 & 7,71 & 0,31
\end{tabular}

Setelah diamati bahwa dimensi rata - rata fender mobil Esemka Rajawali II adalah 2470,24 $\mathrm{mm}$ pada alat ukur 3D manual tercatat lebih tinggi dari 3D laser scanner measurement arms, yaitu: $2462,53 \mathrm{~mm}$. Selain itu, perbedaan rata - rata fender dengan menggunakan dua metode pengukuran yang berbeda adalah $7,71 \mathrm{~mm}$.

Perbedaan dimesi hasil pengukuran fender dapat disebabkan adanya kesalahan pada masing - masing tahapan dalam melakukan reverse engineering. Penyebab perbedaan tersebut antara lain:

\section{Tahapan Pengukuran (scanning)}

Pada alat ukur 3D manual mempunyai tingkat kepresisian yang rendah, yaitu sekitar 1 mm sedangkan 3D (LSAMA)mempunyai tingkat kepresisian yang lebih baik, yaitu antara $0,01-0,02 \mathrm{~mm}$. Pengukuran dengan menggunakan alat ukur 3D manual sangat tergantung dengan keahlian serta ketelitian dari operator. Keterbatasan dalam hal penglihatan, kondisi fisik serta waktu yang lama selama proses pengukuran tidak menutup kemungkinan terjadi kesalahan pada proses pengukuran fender tersebut (Human Error).

2. Tahapan Pengolahan Data

Tahapan pengolahan data dari alat ukur 3D manual meliputi kesalahan dalam hal penghalusan kurva, data yang kurang tepat harus dilakukan interpolasi data dan pengurangan maupun penambahan jumlah point agar menghasilkan kehalusan pada kurva.

Tahapan pengolahan data dari 3D (LSAMA)mempunyai kendala dalam hal pelapisan warna putih doop pada fender. Perlu dilakukan eksperimen agar cat putih doop yang digunakan bersifat sementara hanya untuk kepentingan proses scanning, tanpa merusak warna asli dari fender mobil Esemka Rajawali II tersebut.

3. Tahapan Pembuatan engineering drawing 3Dsurface fender dan Membandingkan Hasil Pengukuran Dengan Menggunakan Coordinate Measuring 3D Manual dan 3D Laser Scanner Articulated Measurement Arms.

Pada tahapan ini, jumlah point yang didapatkan dari scanning 3D(LSAMA)berjumlah sekitar 180 ribu point. Dengan jumlah tersebut tidak memungkinkan untuk melakukan 
pengukuran dengan jumlah point yang sama bila digunakan alat ukur 3D manual. Solusi yang ditempuh diantaranya dengan mengambil sampel point sejumlah yang dimungkinkan untuk dilakukan dengan menggunakan alat ukur 3D manual. Adapun jumlah serta letak dari point ditentukan secara random.

Secara keseluruhan hasil pengukuran (scanning) dengan menggunakan 3D (LSAMA) lebih akurat dibandingkan pengukuran (scanning) dengan menggunakan alat ukur 3D manual. Hal tersebut disebabkan pengukuran dengan 3D (LSAMA)dihasilkan point dengan jumlah yang sangat banyak sehingga mendekati dengan ukuran asli dari fender mobil Esemka Rajawali II.

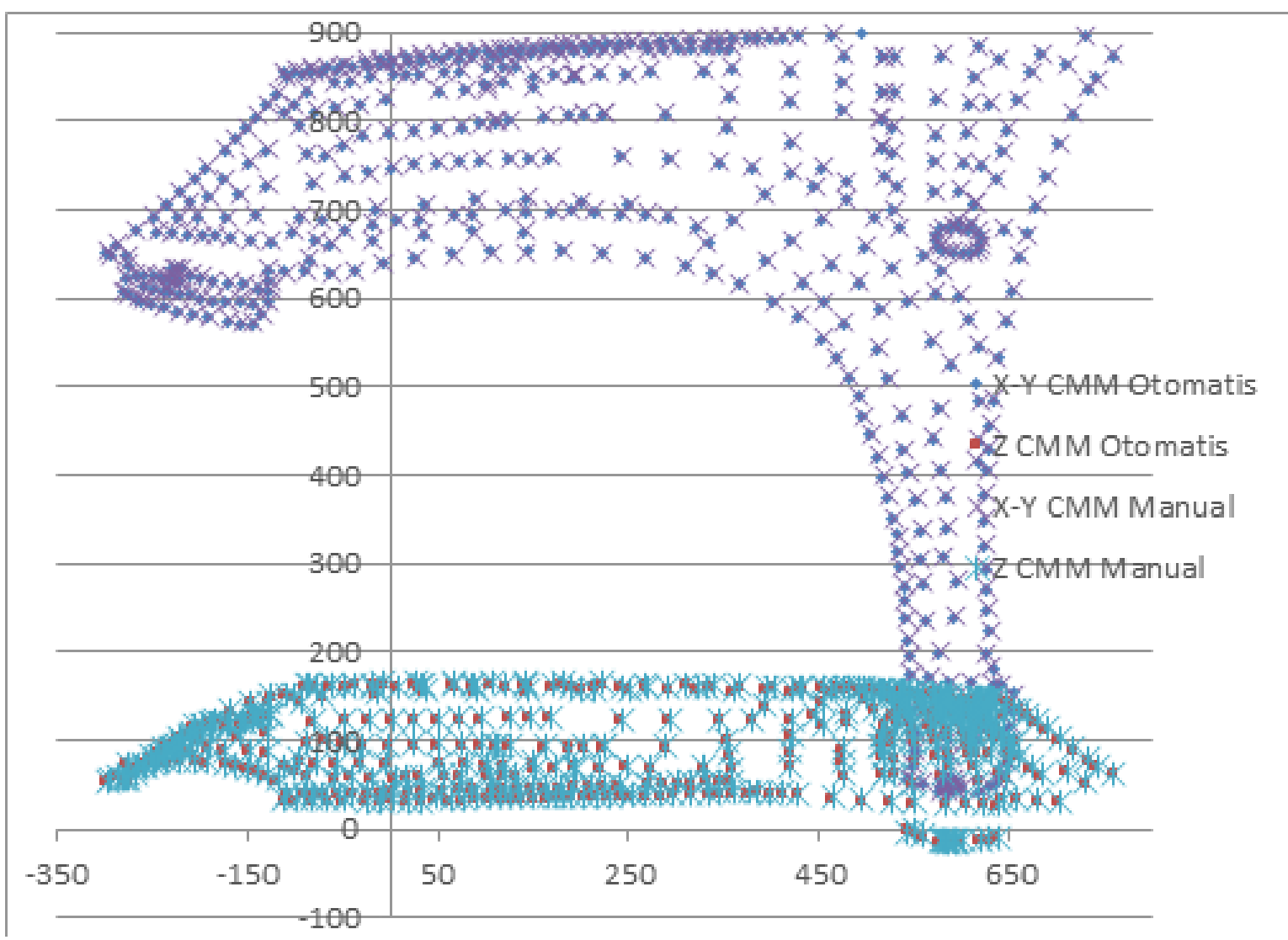

Gambar 12. Grafik hasil pengukuran surface berdasarkan titik koordinat

\section{KESIMPULAN}

Berdasarkan reverse engineering yang telah dilakukan dengan menggunakan dua alat pengukur yang berbeda, maka dapat disimpulkan:

1. Engineering Drawing Fender mobil Esemka Rajawali II didapatkan cara scanning dari fender maupun dengan cara pengolahan titik koordinat dengan menggunakan softwere solidworks.

2. Perbedaan hasil ukur dari alat ukur 3D manual dengan 3D Laser ScannerArticulated Measurement Arms pada dimensi panjang fender 2,08 mm (1060,25 mm - 1058,17 mm). perbedaan lebar fender adalah 3,34 $\mathrm{mm}(180,12 \mathrm{~mm}-176,78 \mathrm{~mm})$. Selain itu selisih pemgukuran pada tinggi dari fender adalah $6,11 \mathrm{~mm}(886,23 \mathrm{~mm}-880,12 \mathrm{~mm})$. Tinggi lengkungan dudukan lampu depan adalah $1,03 \mathrm{~mm}(207,33 \mathrm{~mm}-206,3 \mathrm{~mm})$. Lebar fender bagian atas adalah 2,79 $\mathrm{mm}$ ( 140,13 $\mathrm{mm}-137,34 \mathrm{~mm})$.

3. Jumlah point yang digunakan sebanyak 484 point, dengan jumlah point tersebut diharapkan mampu untuk menerangkan serta membuat bentuk surface dari komponen fender yang hampir menyerupai bentuk asli dari mobil Esemka tersebut. 
4. Adapun penomoran point pada fender dilakukan agar dalam pembacaan titik koordinat pada komputer baik dengan menggunakan alat ukur 3D manual maupun 3D Laser ScannerArticulated Measurement Arms tersebut dapat lebih mudah untuk dilakukan.

\section{DAFTAR PUSTAKA}

[1] Manzoor Hussain, Sambasiva Rao, Prasad, 2008. " Reverse Engineering: Point Cloud Generation With CMM For Part Modeling and Error Analysis". ARPN Journal of Engineering and A pplied Sciences, India, Vol. 3, No.4 Agust 2008, p. 37-40.

[2] Matej Paulic, TomazIrgolic,Joze Balic, Franc Cus, Andrej Cupar, Tomaz Brajlih, Igor Drstvensek, 2013. "Reverse Engineering of Parts with Optical Scanning and Additive Manufacturing”. ScienceDirect, Slovenia, Procedia Engineering 69 (2014) 795-803.

[3] Bambang Waluyo Febriantoko. "Reverse Engineering Sebagai Basis Desain Pengembangan Mobil Mini Truck Esemka" Prosiding Seminar Nasional Aplikasi Sains \& Teknologi (SNAST) Periode III ISSN: 1979-911X Yogyakarta, 3 November 2012. P 318-324.

[4] Antonio Piratelli-Filho,Pedro Henrique Jobim Souza, Rosenda Valdes Arencibia, Nabil Anwer "Study of Contact and Non Contact Measurement Techniques Applied to Reverse Engineering Of Complex Free From Parts" International Journal of Mechanical Engineering and Automation, Ethan Publishing Company, 2014, pp.10.

[5] Piratelli-Filho, A., Souza, P.H.J., Arencibia, R.V., \& Anwer, N., (2014). Study of Contact and Non Contact Measurement Techniques Applied to Reverse Engineering Of Complex Free From Parts. International Journal of Mechanical Engineering and Automation, 10.

[6] Abdil Kus. "Implementation of 3D Optical Scanning Technology for Automotive Applications". Turkey. Sensors 2009 , Vol 9. P 1967-1979. 